\title{
EDITORIAL
}

\section{El reto de la igualdad laboral en la era post Covid}

Eva MaRía Blázquez Agudo

Fundadora Revista Femeris

ORCID ID: 0000-0002-8214-1960

En el contexto previo a la post-pandemia, se edita el tercer número especial de la Revista Femeris, que se publica en colaboración con la Asociación Española de Derecho del Trabajo y de la Seguridad Social. Teniendo, por tanto, otra nueva oportunidad para analizar los asuntos más candentes sobre la igualdad de género en el mercado laboral.

Mucho se ha hablado sobre si la pandemia ha afectado a los derechos de las mujeres. En todo caso, lo que parece indiscutible es que las trabajadoras se han llevado la peor parte de este período (EUROFOUND, Living, working and Covid-19: Impacto on gender equality, marzo 20219). Se ha puesto de manifiesto que las responsabilidades familiares, que soportan de forma usual las trabajadoras, en tiempos de confinamiento se han incrementado, debido a que junto a su actividad laboral han tenido que asumir permanentemente labores de cuidado de su familia, funciones a las que se ha añadido la de "docente auxiliar". Mientras que los/as hijos/as han tenido que seguir sus clases desde casa, han requerido igualmente el apoyo continuo en su escolaridad, añadiéndose esta tarea a las ya comunes de cuidados familiares. Una vez más, se ha puesto de manifiesto la dificultad de compaginar la vida familiar y laboral, en este caso, en un contexto especial que ha llevado a la convivencia permanente de la familia y a la mezcolanza continua de ambas facetas de la vida.

La consecuencia más común de la situación provocada por la pandemia ha sido la reducción de horas de trabajo por parte de las mujeres por razón de cuidado de dependientes, con la consabida aminoración de retribuciones. Pero, la obligada conciliación también ha provocado importantes trastornos de salud como consecuencia de los nuevos riesgos psicosociales que se han surgido durante la pandemia.

En todo caso, después de todo, es posible que esta situación quizás también deje algún aspecto positivo, como puede ser poner en evidencia los esfuerzos que la atención de las responsabilidades familiares implica para las personas trabajadoras. Es decir, el re- 
conocimiento por parte de la sociedad y de todos los progenitores del valor de las labores de cuidado, al haber asistido de forma directa a las complicaciones de las tareas familiares que se han tenido que superarse día a día.

Con independencia de estas cuestiones, más sociológicas que jurídicas, varias son las modificaciones legislativas que se han llevado a cabo en esta etapa relacionadas con la asunción de las responsabilidades familiares. Empezando por el Real- Decreto 8/2020, de 17 de marzo, de medidas urgentes extraordinarias para hacer frente al impacto económico y social del COVID-19, el cual incluyó medidas destinadas a las personas trabajadoras y a sus familias, estableciendo como preferente el trabajo a distancia, en este momento sí con el objeto de conciliar con la situación de confinamiento, donde los/as hijos/as no asistían presencialmente a la escuela; o el Plan MECUIDA, donde ser reconocía respecto a los familiares por consanguinidad hasta el segundo grado el derecho a la adaptación de la jornada y/o reducción de la misma, cuando concurriesen circunstancias excepcionales relacionadas con las actuaciones necesarias para evitar la trasmisión comunitaria del coronavirus. En este Plan, se echó en falta el estabelecimiento de compensaciones económicas en los supuestos de reducciones a la jornada con el fin de no aminorar el salario de las personas cuidadoras, que, en general, han sido mujeres. Puesto que finalmente su puesta en marcha vuelve a producir el efecto indirecto de que sean ellas, que son las que se hacen cargo de los cuidados, quienes reduzcan sus salarios, acentuando las diferencias retributivas por razón de género.

La organización del trabajo durante la pandemia también ha precipitado la aprobación del Real Decreto- ley 28/2020, de 22 de septiembre, de trabajo a distancia. No obstante, antes de avanzar, hay que señalar que el teletrabajo es una forma de organizar el tiempo de trabajo. Lo que se ha vivido durante el confinamiento no ha sido teletrabajo, sino que ha supuesto una suerte de imbricación constante de la vida laboral y familiar, casi de supervivencia diaria, en una situación muy distinta a la cotidiana. Solo se empezó a desarrollar, tal y como se establece en la norma, cuando se reestablecieron las clases y la vida familiar volvió a la casi normalidad. No obstante, ha servido para fomentar una forma de trabajar que parecía estancada y que ha puesto de manifiesto sus virtualidades durante la pandemia.

La Exposición de Motivos del Real Decreto-ley 28/2020 señala, desde mi punto de vista de forma errónea, la relación del teletrabajo con la conciliación familiar. Hay que advertir que, si bien la flexibilidad que aporta colabora en este espacio, esto no significa que se constituya en acción de esta naturaleza. Si se equipara teletrabajo con una medida de conciliación, finalmente serán las mujeres las que utilicen esta forma de organización del trabajo con este fin, y serán ellas de nuevo las que sufran los inconvenientes del teletrabajo, siempre que no se coordine de forma mixta con jornadas de trabajo presenciales, que pueden conllevar la pérdida del aprendizaje por contacto con el resto del personal, efectos de los riesgos psicosociales y aumento de las dificultades para promocionar en la empresa. Todo esto redundará, seguramente, en el aumento de la brecha salarial.

Con independencia de la pandemia, pero coincidiendo en el tiempo, el Real Decreto $902 / 2020$, de 13 de octubre, de igualdad retributiva entre mujeres y hombres, ha obligado a las empresas a desarrollar un registro salarial en aras a garantizar que hombres y 
mujeres son remunerados de la misma forma por trabajos de igual valor. Asimismo, se ha regulado el deber de auditoria salarial para aquellas empresas que deben desarrollar un plan de igualdad, todas las que tienen al menos 50 personas trabajadoras, cuando finalice la transitoria, que tiene como objeto también detectar el incumplimiento de esta desigualdad en el salario.

Seguramente con todas estas medidas se consiga la finalidad indicada: la igual remuneración por trabajos de igual valor. Pero, solo con ellas, no se alcanzará la superación absoluta de la desigualdad salarial. La brecha salarial no es monocausal. Su existencia está motivada por diversos elementos. En todo caso, es en gran parte el efecto de la posición de la mujer en el mercado laboral: su excesiva presencia en sectores con baja remuneración, infrarrepresentada en el ámbito de la ciencia, tecnología e ingeniería; de la mayor proporción en el trabajo a tiempo parcial; y de las menores opciones de promocionar, esto es, el llamado "techo de cristal", que impide que las mujeres asciendan no ya solo al ámbito de la dirección, sino incluso al de los mandos medios. Y este es un elemento fundamental que analizar y al que buscar causas y soluciones: los efectos de las limitaciones en la promoción y ascenso de las mujeres y sus consecuencias en la brecha salarial.

Como es fácil concluir, la única diferencia real entre los hombres y las mujeres es una cuestión biológica: la maternidad. Sus potenciales consecuencias en la vida laboral llevan a que las mujeres puedan ser vistas como menos productivas en los momentos de su vida en que se encargan de los cuidados familiares y optan por emplear las medidas de adaptación a la jornada o reducción de esta por ser la mejor solución económica para la familia.

Si bien es verdad que la equiparación de los permisos de nacimiento para ambos progenitores ha resuelto esta cuestión durante los primeros momentos del cuidado, queda aún por solventar la atención de los/as hijos/as hasta los 12 años. En general, siguen siendo las mujeres las que reducen su jornada por este motivo y esta opción no solo aminora proporcionalmente su salario, sino también sus posibilidades reales de promoción. Pero, asimismo son quienes asumen la atención en caso de enfermedad, el acompañamiento a consultas médicas o las relaciones con el colegio, entre otras. Y, en esta lógica, como se ha señalado, han sido las que se han hecho cargo de los cuidados de los/as menores durante la pandemia.

Como dentro del núcleo familiar las mujeres son las que menor retribución tienen, son ellas las que se encargan de las tareas de cuidado, puesto que la reducción de sus salarios, inciden menos en el presupuesto económico de la familia. Así, como un circulo sin fin, las mujeres se encargan los cuidados y, en su caso, aminoran sus jornadas de trabajo, reduciendo sus sueldos; y como sus retribuciones son más reducidas, siguen siendo ellas las que se ocupan de los cuidados. Y como se asocian los cuidados con las mujeres, de la misma forma asumen esta tarea respecto a los dependientes.

Frente a esta situación, solamente hay un camino hacia la igualdad de oportunidades entre hombre y mujer: la flexibilidad de la jornada laboral y la corresponsabilidad. Ambas cuestiones están muy relacionadas.

En primer lugar, los cuidados, sobre todo dada la baja tasa de natalidad española, es una tarea que debe ser asumida por todos: obviamente por ambos progenitores, pero 
también por la empresa. En este sentido, es precisa la asunción empresarial de las medidas de conciliación familiar y laboral no como una carga, sino como una oportunidad de mejora del clima laboral, de compromiso de las personas trabajadoras con su trabajo y, consecuentemente, como un elemento que incrementa su productividad y su competitividad. Con este objetivo es preciso poner en marcha medidas de flexibilidad de la jornada que permitan a las personas trabajadoras atender a sus responsabilidades familiares, sin necesidad de solicitar la reducción de jornada. Esto es, ir un poco más allá de la adaptación de jornada que debe solicitarse por la persona trabajadora, e incorporarse en los convenios colectivos o, incluso, como práctica de la empresa, la posibilidad de flexibilizar la jornada, en el momento concreto que sea preciso, para compatibilizar la vida familiar y laboral, e incluso la personal, siempre con las excepciones lógicas que imponga la actividad desarrollada y las necesidades de la empresa.

Pero, además, las Administraciones públicas también deben implicarse en este asunto, estableciendo medidas con el fin de reducir la feminización de los cuidados. Es decir, con la incorporación de políticas que faciliten estas tareas reduciendo el esfuerzo económico a las familias. En definitiva, la corresponsabilidad es una tarea de toda la sociedad.

Solamente cuando el cuidado sea asumido de forma igualitaria por hombres y mujeres, cuando exista libertad absoluta, sin ningún otro condicionante como la pérdida salarial, para desarrollar estas labores, será posible alcanzar la igualdad laboral en todos los aspectos, incluidos los salariales. Y en este contexto hay que asumir los retos que el mercado laboral presenta en la era post-Covid, al que aportan valiosas soluciones los contenidos de este número que ahora se presenta.

En este número de FEMERIS, que una vez más, gira en torno al acto institucional de la Asociación Española de Derecho del Trabajo y de la Seguridad Social del Día Internacional de la Mujer, se afronta un elemento importante en el contexto descrito, que no es otro que la "Igualdad de género, sistema de clasificación profesional y valoración de puestos de trabajo". Esta vez el evento se desarrolló en colaboración con el Consejo Económico y Social y la Universidad Rey Juan Carlos de Madrid. Y, no quedó más remedio por razones sanitarias, que celebrarlo en modalidad online, lo cual, no obstante, no restó calidad al acto, sino que, al revés, permitió que muchas personas, que no podrían haberse trasladado hasta Madrid para asistir, pudieran hacerlo de forma cómoda desde su lugar de origen.

En la línea presentada, de las dificultades en la promoción y ascenso de las trabajadoras, la primera ponencia de esta jornada, publicada en este número como el primero de siete artículos, fue a cargo de la profesora Fabregat y llevaba por título "Criterios y sistemas de promoción profesional y ascensos y no discriminación por razón de género", donde analizó la discriminación por razón de sexo en el ámbito de la promoción profesional, poniendo el acento en las causas que promueven la segregación horizontal y vertical en el mercado de trabajo e impiden a las mujeres promocionar profesionalmente. Asimismo, se centró en el valor que la negociación colectiva podría tener en el ámbito del proceso de selección con el fin de garantizar la objetividad en la contratación.

Como segundo artículo de este número, se encuentra la aportación de la profesora Marín Malo, que lleva por título "Discriminación salarial indirecta y los sistemas de valora- 
ción de puestos de trabajo", que además fue el que obtuvo el premio de investigación sobre igualdad y no discriminación que concede cada año la AEDTSS por el Día Internacional de la Mujer. Este magnífico trabajo, que ha merecido esta calificación, parte de la premisa que la desigual valoración de puestos de trabajo es una de las causas que explican la brecha salarial de género. Apuesta por dar un paso más en la identificación de situaciones de discriminación salarial, apostando por incorporar sistemas de valoración de puestos de trabajo neutros desde la perspectiva de género.

La profesora García Gil, en un tercer artículo, "Valoración de puestos de trabajo con perspectiva de género", presenta como la desigualdad salarial entre hombres y mujeres en las relaciones laborales tiene una relación directa con la valoración de puestos de trabajo. Este trabajo se origina también en una ponencia presentada en el acto de la AEDTSS del Día Internacional de la Mujer, y se centra en demostrar que la valoración de los puestos de trabajo es una herramienta fundamental en la visualización de las diferencias retributivas de las mujeres y los hombres, cuando realizan un mismo trabajo o de trabajos distintos, pero de igual valor; y que debe constituirse como una evaluación objetiva del puesto, independientemente de la persona que lo ocupe.

Posteriormente, se puede leer el artículo de la magistrada Fernández Galiño y el magistrado Lousada Arochena quienes analizan, a través del trabajo “Covid-19 e igualdad de género", el impacto de la pandemia desde una triple perspectiva: las consecuencias de la enfermedad sobre la salud de las personas; las del confinamiento y medidas acordadas para combatir la enfermedad; y, por último, las sociales, laborales y económicas derivadas de la enfermedad. Todo esto con el fin de concluir que la pandemia ha puesto en riesgo la igualdad, pero también se ha convertido en la oportunidad de los poderes públicos de introducir la perspectiva de género en la reconstrucción del mercado laboral.

En la misma línea, la profesora Poquet Catalá, con su artículo “AAvances en la lucha contra la discriminación salarial por razón de sexo?”, examina la normativa reciente, tanto nacional como internacional, y la jurisprudencia destinada a promover la igualdad retributiva, aportando una visión completa de esta materia, que pone de manifiesto qué avances se han producido y qué retos quedan aún por desarrollar.

Dejando el hilo conductor del derecho del trabajo, se completa este número con dos artículos. El profesor Padrós, con su trabajo “CCómo avanzar en la lucha por la libertad e igualdad de la mujer: propuestas legales frente a la cosificación, hipersexualización y pornificación de la sociedad", analiza la igualdad desde la represión de los delitos de género y las agresiones sexuales, completando la visión de la igualdad a través de los fenómenos de la hipersexualización y la cosificación de la mujer, y poniendo de manifiesto como la disponibilidad absoluta de contenidos pornográficos, cada vez más violentos y vejatorios contra las mujeres, frenan la consecución de la igualdad. La solución que aporta ante esta realidad es la puesta en marcha de medidas preventivas, el control de su contenido, la limitación de su acceso, así como la aplicación de las figuras penales de la inducción o la apología respecto a la difusión de contenidos ilícitos; la aplicación del tipo específico del delito de odio por razón de género; y la extensión de la responsabilidad de quienes alojen estos contenidos en la red. 
Por último, Alfonso Toribio, con "Apuntes para la erradicación de la violencia de las mujeres en España", aborda la violencia de género desde su conceptualización y diferenciación entre sexo y género, desde el análisis de la perspectiva detallada del caso español a través del análisis jurídico de la Ley 1/2004 y el Convenio de Estambul.

Asimismo, fuera ya de los artículos, en la sección de Misceláneas se incluye un análisis del "retrato de Manuela Carmena en ABC durante sus primeros cien días como alcaldesa", cuya autora es la profesora Carrascosa Puertas.

Este número se complementa con la sección clásica de las crónicas jurisprudenciales en la materia; y la presentación del contenido de jornadas destacadas como la titulada "Por un empleo digno en el sector de cuidados: Superando los roles de género", dirigida por la profesora Rodríguez Escanciano y la del acto de la AEDTSS por el Día Mundial de la Mujer, que ya ha sido referenciado. Su última parte se dedica al comentario de las novedades bibliográficas en igualdad y mercado laboral: Grau Pineda, C., La brecha de pensiones en España, Albacete, Bomarzo, 2021; Sierra Hernáiz, E./Valleja Dacosta, R. (Directoras); Diseño e implementación de planes de igualdad en las empresas, Navarra, Aranzadi, 2020; Ventura Franch, A./Iglesias Bárez, M. (Coords.), Manual de Derecho Constitucional Español con Perspectiva de Género, Ediciones Universidad de Salamanca, Salamanca, 2020; y Aragón Gómez, C./ Nieto Rojas, P., Planes de igualdad en las empresas. Procedimiento de elaboración e implantación, Madrid, Wolters Kluwer, 2021.

Muchas gracias por todos estos contenidos que contribuyen una vez más a la promoción de la igualdad de la mujer en el mercado laboral desde distintos puntos de vista, apuntando soluciones valiosas que poner en marcha con este fin. 